\title{
As marcas da enunciação no cinema
}

/IIII/IIIII Egle Müller Spinelli

Universidade Anhembi Morumbi 
Resumo Este artigo propõe uma reflexão sobre os conceitos de enunciado e enunciação no cinema. Estes termos foram inicialmente concebidos pela lingüística e, posteriormente, transpostos para discussões teóricas ligadas ao cinema. Existem filmes que atestam a presença da enunciação no enunciado, um fator que permite atualizar o sentido da obra por meio de mecanismos que revelam o próprio ato produtor do filme. De maneira sucinta, pretende-se fornecer um panorama sobre as possibilidades de ocorrência de enunciações enunciadas na composição das narrativas audiovisuais.

\section{Palavras-chave}

enunciação, enunciado, cinema

\section{Abstract}

The aim of this article is to make a reflection on the concepts of enunciated and enunciation which occur in the cinema. These terms were initially designed by linguistics and subsequently were translated into theoretical discussions related to cinema. There are movies that attest the presence of the enunciation in the enunciated, a fact that allows to updating the meaning of the work through mechanisms which reveal the act itself produced by the film. Thus, the focus of this work consists in providing an overview about how enunciations are structured in the composition of the audiovisual narrative.

\section{Key-words}

enunciation, enunciated, cinema 
A enunciação é o ato produtor do enunciado, e como já colocado por Benveniste, é uma instância de mediação que assegura a discursivização da língua, que permite a passagem da competência à performance, das estruturas semióticas virtuais às estruturas realizadas sob a forma de discurso. Benveniste (2008, p. 80) diz que "a enunciação é essa colocação em funcionamento da língua por um ato individual de utilização". Já Anscombre (1988, p. 18) defende a idéia de que "a enunciação é uma atividade exercida por aquele que fala no momento em que fala, ligada à ordem do acontecimento e, como tal, não se reproduz nunca duas vezes idêntica a si mesma". Colocada como um ato singular, o estudo da enunciação não consegue se sustentar por ele próprio, pela impossibilidade de se constituir um objeto científico. Como demonstra Catherine Kerbrat-Orecchioni (1980, pp. 29-30), o linguísta não mais opõe "a enunciação ao enunciado como o ato a seu produto, um processo dinâmico a seu resultado estático", mas, impossibilitado de estudar diretamente o ato da enunciação, busca identificar e descrever os traços do ato no produto.

Nesta perspectiva, Greimas e Coutés (apud GAUDREAULT, p. 126) definem a enunciação como a instância constitutiva e pressuposta pela própria existência do enunciado, a qual comporta seus traços e suas marcas. O enunciado, por oposição à enunciação, deve ser concebido como o estado que dela resulta, independentemente de suas dimensões sintagmáticas. Assim, o enunciado linguístico pode comportar elementos que remetem à instância da enunciação, exemplificada pelos pronomes pessoais, demonstrativos, possessivos, adjetivos e advérbios apreciativos, dêiticos espaciais e tempo- 
rais, entre outros. Em síntese, existem textos sem nenhuma marca de enunciação, que simplesmente se apresentam como um "enunciado enunciado", e textos que remetem à instância da enunciação, o que se denomina por "enunciação enunciada”.

A enunciação também pode ser analisada como a instância de instauração do sujeito no discurso, onde o "eu é pronunciado e designa o seu locutor" (BENVENISTE, 2008, p. 261-2). Como a pessoa enuncia em um dado espaço e em um determinado tempo, todo espaço e todo tempo organizam-se em torno do "sujeito", que por sua vez, é tomado como ponto de referência. A partir do espaço e do tempo da enunciação, organizam-se todas as relações espaciais e temporais da narrativa. Fiorin (1992, p. 42) diz que "a enunciação é o lugar de instauração do sujeito e este é o ponto de referência das relações espaço-temporais".

O enunciado ${ }^{1}$ corresponde ao texto fílmico onde os significados (códigos) são identificados com facilidade pelo espectador. A presença da enunciação no cinema, diferentemente da lingüística, é difícil de ser identificada, pois para que ela exista pressupõe-se um sujeito que enuncia e outro que receba esta enunciação. Porém, no cinema o sujeito da enunciação, muitas vezes, aparece ausente do enunciado quando, por exemplo, os acontecimentos se contam por eles mesmos (não existe um "eu” e/ou um "ele" que narrem claramente a história). Assim, é possível encontrar várias definições da enunciação fílmica.

Emile Benveniste (apud FEVRY, p. 96), baseado na enunciação linguística, coloca a enunciação cinematográfica como "a apropriação das possibilidades expressivas oferecidas ao cinema, a fim de dar corpo e consistência a um filme”. Segundo o Dicionário de Greimas e Courtés, a enunciação é definida como um ato de produção e uma passagem de uma instância virtual (como um código) a uma instância real. Por outro lado, Metz (apud VANOYE e GOLIOT-LÉTÉ, p. 44) coloca que os indícios da enunciação de um texto se encontram dentro do próprio texto e acrescenta que é o próprio filme que se "enuncia" por meio de "construções reflexivas". Isso ocorre quando "o filme nos fala dele mesmo, ou do cinema, ou da posição do espectador”, que desvenda os segredos de seu dispositivo enunciativo. O enunciado se "desdobra”, "curva-se sobre si mesmo" e fala da situação de sua produção. Casetti (1989) engloba as idéias descritas acima e amplia o campo da enunciação
1. Casetti (1989, pp. 42-3) usa o termo enunciado para designar qualquer unidade no plano da realização audiovisual: imagem, seqüência, filme, etc. Esta extensão está justificada também pela ausência de uma terminologia adequada no campo do cinema. 
colocando-a como uma instância que abre um campo de significação, pois o significado dado ao enunciado fílmico leva em conta a participação ativa do espectador.

A enunciação além de fazer referência ao próprio texto fílmico, muitas vezes, deixa de lado a história que é contada e se atém a mostrar como esta história é contada. Isto ocorre ao enfatizar o discurso produzido pelas relações entre os enunciados e suas instâncias produtivas que remetem a seus pressupostos, bem como a outros contextos produzidos por outros enunciados, referentes ao filme ou, até mesmo, ao espectador.

\section{A aplicação do conceito de enunciação no cinema}

Por meio do estudo da enunciação é possível articular o discurso com suas condições de produção, realizando uma análise do texto juntamente com sua inserção no seu contexto. A análise da estrutura da enunciação vem fornecer subsídios para estabelecer um vínculo entre o discurso e suas próprias condições sócio-históricas de produção e recepção. O texto fílmico será analisado levando em consideração suas ligações intertextuais, ou seja, como um texto maior que tem embutido no seu contexto a soma de outros textos, uma totalidade de significação. Não se trata, portanto, de ler o conteúdo do texto fílmico na sua totalidade, mas sim estabelecer recortes suscitados pelas relações temporais e espaciais que se estabelecem.

Christian Metz (1991) afirma explicitamente no seu livro L'enunciation impersonnelle ou le site du film que a enunciação

2. Chama-se dêitico qualquer marca, qualquer indicador que remete tanto ao locutor quanto à situação de enunciação. Os mais comuns são os pronomes pessoais, os pronomes e adjetivos possessivos e demonstrativos, os advérbios de tempo e de lugar e os tempos dos verbos. fílmica não apresenta uma natureza antropomórfica como aparenta ter a enunciação verbal. As instâncias que compõem um filme parecem intuir uma natureza humana, principalmente quando existe a intenção de encontrar na obra o seu referido autor ou espectador. Isto se deve aos estudos que se baseiam em transferir para o domínio fílmico o caráter enunciativo do sistema verbal, fundamentado no aparelho dêitico². Segundo Cervoni:

Toda enunciação verbal supõe um locutor e um alocutário; ela se dá no tempo, em um determinado momento; os actantes da enunciação (locutor e alocutário) encontram-se no espaço, em um determinado lugar, no momento em que ela ocorre. (1989, p. 23) 
No sistema linguístico, uma frase como "Eu estou lhe contando agora a história do livro que li ontem", apresenta o verbo "estou contando" no tempo presente, o que remete a uma enunciação que ocorre no presente; o verbo "li", no tempo passado, refere-se a um passado relativo ao presente da enunciação; o pronome pessoal "eu" liga-se ao locutor; o pronome "lhe" que indica o alocutário; os advérbios de tempo "agora" e "ontem", que remetem, respectivamente, ao presente e ao passado da enunciação. A partir deste modelo, tentou-se denominar o "eu" como a fonte da enunciação literária e "você", seu alvo, considerando o texto como o lugar de uma conversa indireta entre a fonte e o alvo da enunciação.

A crítica de Metz recai sobre a questão de se comparar à análise dos textos verbais como, por exemplo, as partes dialogadas de um romance, com os diálogos fílmicos. No texto verbal, os dêiticos oferecem informações sobre a enunciação através da própria enunciação, de forma diferente dos textos fílmicos, onde os dêiticos dos diálogos fornecem referências não sobre a enunciação do filme, mas sobre uma enunciação interna, ela própria enunciada pelo filme. O romance é um sistema de códigos que tem a particularidade de apresentar uma estrutura verbal do começo ao fim, diferente do filme, que é constituído de uma matéria amplamente extra-linguística. Muitos teóricos chegam a dizer que a enunciação só pode ser aplicada à palavra e à escrita, mas Metz (1991, p.19) defende a idéia de que é possível estabelecer certas referências conectadas à enunciação fílmica:

[...] conquanto que o filme seja estabelecido como um aparelho enunciativo que não seja essencialmente dêitico (antropomórfico), pessoal (como os pronomes assim denominados) e que não imite determinados dispositivos linguísticos.

Assim, o autor propõe substituir os termos "enunciador" e "enunciatário", cujo sufixo refere-se demais a um caráter antropomórfico, por "foco da enunciação" e "alvo da enunciação", assumindo um posicionamento mais neutro. Para Metz (1991, p. 20), "a enunciação é um ato em que certas partes do texto nos falam deste texto, o que acontece quando o próprio texto deixa inscrito no seu enunciado as marcas desta enunciação". 
Bettetini faz uma interessante colocação sobre a questão da enunciação no seu livro La Conversazione audiovisiva (1988). O teórico descreve o filme, tal como uma conversação que ocorre entre um simulacro de um emissor e um simulacro de um receptor, os dois estando presentes de uma maneira imaginária (o que chama de ausência) e interativa no texto fílmico e, portanto, constituintes do próprio aparelho de enunciação.

Os estudos de Francesco Casetti (1989) demonstram um posicionamento semelhante ao de Bettetini: a enunciação estabelece uma relação entre um enunciador (aquele que organiza a representação de uma história em discurso) e um enunciatário (sujeito a quem o discurso se dirige) e, este último, é colocado como um interlocutor que tem uma trajetória, estabelecida pelo filme, a ser percorrida. Neste percurso, o interlocutor não é um mero decodificador, e sim um participante ativo que atualiza o filme através de um processo de interação com ele. Porém, Casetti não aceita o termo ausência denominado por Bettetini: diz que a ausência significa a anulação da presença do sujeito da enunciação. Este sujeito existe e durante o filme assume o tempo e o espaço de uma percepção, de um saber e de um crer. Para Casetti, a enunciação é definida como:

3. A questão sobre o ponto de vista é amplamente estudada como uma marca da operação lingüística, mas podem ser encontrados diversos estudos na área de cinema que abordam o tema. Ver livros de S. Chatman, Story and Discourse, Cornell University Press, 1978; de E. Branigen, Point of View in the Cinema, Berlin-Nova York, Amsterdam, Month, 1984. O estudo do ponto de vista tem como função desvendar quem é o responsável pela articulação da representação instaurada no discurso. O ponto de vista é um sinal de que a imagem está organizada por e para um olho colocado diante dela.
[...\} a conversão de uma língua em discurso, ou seja, a passagem de um conjunto de simples virtualidades a um objeto concreto e localizado: objeto concreto, enquanto realidade perceptível; objeto localizado, enquanto coisa que aparece no mundo. Em outras palavras, a enunciação é o apropriar-se e o apoderar-se das possibilidades expressivas oferecidas pelo cinema para dar corpo e consistência a um filme. (1989, pp. 41-2)

Casetti defende a ideia de que sempre existem elementos no enunciado fílmico que reproduzem a enunciação e, por conseguinte, o seu sujeito, atestando assim suas presenças. Para ele, estes elementos estão ligados sob o ponto de vista ${ }^{3}$ do qual se observam as coisas, relativo ao olhar que institui e organiza a cena, a ótica que delimita e determina o enquadramento, a uma palavra ou uma música, ou seja, tudo o que está ligado às imagens e sons e que, conjuntamente, determinam suas coordenadas e seus perfis. 


\section{As marcas da enunciação no enunciado fílmico}

No cinema, o filme é organizado por meio de diversos pontos de vista que são construídos perante determinada representação. $\mathrm{O}$ modo como uma imagem e/ou som é construído define uma relação entre a maneira como algo é mostrado e a maneira como este recorte é visualizado, isto é, o ponto de vista enquadrado pela câmera com relação ao olhar do espectador. Por exemplo, a utilização de angulações ${ }^{4}$ de câmera inusitadas, onde ela assume posicionamentos que não correspondem ao padrão normal de se olhar o mundo, coloca o espectador frente a um ponto de vista que é difícil de ser atribuído a algum personagem, o que provoca um estranhamento que pode reportar a enunciação fílmica. Por exemplo, na sequência inicial do filme A Marca da Maldade (Touch of Devil, 1958), de Orson Wells, a câmera em plano-sequência realiza um movimento de cima para baixo e acompanha a movimentação dos protagonistas principais que cruzam a fronteira entre os Estados Unidos e o México, até a explosão de um carro. Este plano, além de causar uma inquietação por ser construído em plano-sequência (sem cortes), atesta para um olhar que não corresponde a uma visão normal que se tem da realidade, e que implica no próprio ato de produção do filme, ou seja, na enunciação.

Dessa maneira, é possível começar a pensar no modo como a enunciação deixa determinadas marcas no filme, atestando a sua própria presença no enunciado. Existem filmes, em que a enunciação não se reporta de maneira explícita (enunciado enunciado), ou seja, existe toda uma articulação temporal e espacial que tenta desenvolver uma representação semelhante a qual o espectador vê o mundo. $\mathrm{O}$ espectador assiste ao filme como se fizesse parte daquele contexto, pois a maneira como as imagens e os sons são articulados cria um certo tipo de cumplicidade que faz com que ele se esqueça do próprio mundo e adentre no universo ficcional da narrativa. Os espectadores também estão acostumados com um tipo de representação audiovisual, onde existe uma organização espacial e temporal, tanto dos planos isolados, como da articulação entre os diversos planos que compõem o filme e que conduz o desenrolar dos acontecimentos sem chamar a atenção para as suas condições de produção. O filme é estruturado com o intuito de fazer o espectador acompanhar apenas o fluir da história, sem dar brechas
4. As angulações da câmera costumam ser chamadas de plongée para as câmeras altas e, contra-plongée para as câmeras baixas. 
para que ele perceba como o discurso é organizado pelo dispositivo cinematográfico. Este processo é relacionado aos filmes ficcionais narrativos, onde os fatos são narrados sem que se atestem os recursos que determinam a maneira de narrar, isto é, a enunciação não é evidente no enunciado.

Outra idéia que pode ser discutida, e é a que mais interessa neste presente estudo, é quando se percebe a presença da enunciação no enunciado fílmico (enunciação enunciada). A interpelação nos filmes de ficção, por exemplo, pode ser considerada como um recurso que representa as pistas da enunciação. Este mecanismo ocorre quando os personagens olham em direção à câmera, o que instaura um olhar que olha diretamente nos olhos do enunciatário/espectador. Isto resulta em uma ruptura do espaço diegético instaurada pelos elementos em cena, fazendo com que tanto o enunciatário como o enunciador instalem-se no enunciado, deixem de ser simples testemunhas e passem a ser implicados na ação. Nesta situação, o personagem dirige-se explicitamente para aquele ao qual o filme está destinado. O enunciador e o enunciatário tentam se fazer entender, mas o primeiro assume o papel de um personagem apoiando-se em uma entidade de ação (que é aquele que olha) e em uma identidade de objetivos (apontar em direção àquele que olha para ele), enquanto que o segundo se oferece pelo que é, nada mais que um ponto de vista "ideal". O olhar direto do personagem para o espectador implica na quebra do universo ficcional (diegese), pois é impossível mostrar, subsequentemente, o plano que liga este olhar, que seria o plano referente ao próprio espectador. Este recurso chegou a ser proibido dentre as normas de organização espacial e temporal do chamado cinema hollywoodiano clássico. Porém, é importante frisar que este cinema passou, no decorrer das últimas décadas, a experimentar com a linguagem, utilizando este recurso em diversos filmes: a narrativa pára e os personagens falam diretamente ao espectador. É claro que hoje em dia, o espectador também evoluiu em termos da compreensão de determinados recursos utilizados pela linguagem audiovisual, o que possibilita que as histórias sejam contadas sem muito didatismo. Por exemplo, para compreender que determinado plano equivale a um flashback, não é estritamente necessário que haja fusões que remetem ao seu início e fim, recurso muito utilizado para indicar a passagem do tempo. Um corte seco pode ser usado, sem que cause determinada estranheza ao espectador, atestando ou não a enunciação. 
Além do olhar dos personagens em direção à câmera, a enunciação pode se estabelecer através de outras demarcações, como a utilização da voz off ou da voz over, vozes em que a fonte de emissão não é vista na tela. A voz off refere-se à voz de algum personagem da história que é identificado pelo espectador. Já a voz over apresenta um emissor que é desconhecido. Estas vozes podem remeter a outro tempo e/ou espaço, além do discorrido na narrativa. Por exemplo, no início do filme Ensaio de um Crime (1956), de Luis Buñuel, a voz over do personagem principal relata um acontecimento em um tempo/espaço anterior ao tempo da narrativa primeira do filme e o espectador conecta os fatos em um tempo/espaço depois. Porém, estes dois fatos interligam-se em um tempo/espaço presente e, juntos, criam uma ambiguidade de sentidos, o que atesta para uma possível enunciação. Este contexto também engloba a questão dos flashbacks ou flashforwards, recursos ligados à organização temporal e espacial da narrativa que podem ser utilizados de uma maneira que implica uma participação do espectador na construção do sentido da obra, o que novamente recai sobre a questão da enunciação.

As marcas da enunciação no enunciado fílmico podem se manifestar de diversas formas e muitas vezes são criadas pelos realizadores dos filmes para provocar sentidos que escapam ao que é simplesmente enunciado na tela, permitindo ao espectador construir e atualizar novos contextos e ligações dentro e fora do universo ficcional. 


\section{Bibliografia}

ANSCOMBRE, Jean Claude. L'argumentation dans la langue.

Bruxelles: Pierre Mardaga, 1988.

BENVENISTE, Emile. Problemas da lingüística geral I.

Campinas: Pontes Editores, 2008.

BETTETINI, Gianfranco. La conversazione audiovisiva: problemi dell'enunciazione filmica e televisiva. Milano: Bompiani, 1988.

CASETTI, Francesco. El film y su espectador. Madrid: Cátedra, 1989.

CERVONI, Jean. A enunciação. São Paulo: Ática, 1989.

FEVRY, Sébastien. La mise en abyme filmique: essai de typologie.

Liege: Editions du Céfal, 2000.

FIORIN, José Luiz. As astúcias da enunciação: as categorias de pessoa, espaço e tempo. São Paulo: Editora Ática, 1999.

GAUDREAULT, André. Du littéraire au filmique. Système du récit. Paris: Méridiens Klincksieck, 1988.

GREIMAS, Algirdas Julien e COURTÉS, Joseph. Sémiotique: dictionnaire raisonné de la théorie du langage. Paris: Hachete, v. I, 1979.

KERBRAT-ORECCHIONI, Catherine. L'enonciation. De la subjectivité dans le langage. Paris: Armand Colin, 1980.

METZ, Christian. L'enonciation impersonnelle ou le site du film. Paris: Méridiens Klincksieck, 1991.

VANOYE, Francis e GOLIOT-LÉTÉ, Anne. Ensaio sobre a análise fílmica. Campinas: Papirus, 1994. 